\title{
Da renda inglesa aos diamantes do Brasil: as encomendas de D. Maria I a D. Vicente de Sousa Coutinho na corte de Paris ${ }^{1}$
}

From English Lace to Brazilian Diamonds: the Orders of D. Maria I
to $D$. Vicente de Sousa Coutinho at the Court of Paris

Ana Luiza de Castro Pereira Gomes*

\section{RESUMO}

A relação dos usos e costumes que dizem respeito à cultura material, na sociedade portuguesa do século XVIII, vem sendo analisada por investigadores que utilizam uma variada panóplia de documentos, os quais lhes permitem visualizar a vida na corte lisboeta. As correspondências de membros do corpo diplomático têm revelado aspectos interessantes do seu dia a dia. Neste artigo, analisaremos as cartas enviadas de Lisboa a Paris, que consistiram em listas de encomendas feitas por D. Maria I. Os interlocutores são João António Pinto da Silva, o moço da Câmara de Guarda-Roupas e Guarda-Joias, e D. Vicente Coutinho, embaixador na corte parisiense. A diversidade de objetos constantes nas listas, a minúcia das descrições e a preocupação do embaixador em atingir as expectativas da rainha permitem, assim, que seja revelada não somente a circulação material, como a própria cultura material da época. Palavras-chave: D. Maria I; Portugal; Século XVIII; Encomendas régias.

\section{Abstract}

The relationship of the uses and customs that concern the material culture, in the Portuguese society of the 18th century, has been analyzed by researchers who use a wide range of documents that allow them to visualize life at the Lisbon court. The correspondence of members of the diplomatic corps has revealed interesting aspects of their daily lives. In this article, we will analyze the letters sent from Lisbon to Paris, which consisted of lists of orders placed by $\mathrm{D}$. Maria I. The interlocutors are João António Pinto da Silva, the Chamber's Clothes-keeper and Jewel-keeper, and D. Vicente Coutinho, ambassador to the Parisian court. The diversity of objects in the lists, the thoroughness of the descriptions, and the ambassador's concern to meet the queen's expectations reveal not only the material circulation but also the material culture of the time. Keywords: D. Maria I; Portugal; 18th century; Royal orders.

\footnotetext{
* Universidade NOVA de Lisboa (UNL), Lisboa, Portugal. analuizagomes@fcsh.unl.pt aluizacastro@ gmail.com <https://orcid.org/0000-0002-1976-6802>
} 
Bem considero a grande dificuldade que V. $\mathrm{Ex}^{\mathrm{a}}$. encontrará no artigo das rendas, na forma que $\mathrm{V}$. $\mathrm{Ex}^{\mathrm{a}}$. Me participa; mas como V. Ex ${ }^{\mathrm{a}}$. Está em uma corte tão provida de tudo que pertence ao luxo, porque estas são as suas frutuosíssimas Minas; lá poderá dar as providências que julgar precisas a este respeito, ou remediar pelo modo que lhe parecer mais decente, e próprio para a grandeza e decoro da Nossa Augustíssima Ama (Pinto da Silva, Livro 67, fl. 46, 1784).

Assim escreveu, em 1784, José António Pinto da Silva, moço da Câmara de Guarda-Roupas e Guarda-Joias de D. Maria I, a D. Vicente de Sousa Coutinho, embaixador de Portugal na França. Trata-se de uma das inúmeras correspondências enviadas pelo guarda-joias da rainha a Paris, em que eram listados vários objetos que deveriam ser remetidos à corte lisboeta. Tecidos, louças, tapeçarias, diamantes e vestimentas fizeram parte das infindáveis encomendas remetidas de Paris. D. Vicente de Sousa Coutinho foi um dos muitos representantes diplomáticos que, paralelamente às atividades de representação política na assinatura de tratados econômicos e de paz, acabou por desempenhar o papel de "encomendeiro" dos monarcas.

O reinado de D. Maria I, que esteve no trono português entre 1777 e 1816, foi marcado por uma intensa atividade governativa. Seu primeiro ato, na qualidade de rainha, foi exilar Sebastião José de Carvalho e Melo, o Marquês de Pombal, num processo que ficou comumente conhecido como "A Viradeira". Dedicada às obras sociais, ela foi responsável pela criação da Casa Pia de Lisboa. $\mathrm{Na}$ área das ciências, foi responsável pelo envio de missões científicas a África e ao Brasil. A criação da Academia Real das Ciências de Lisboa e da Real Biblioteca Pública da Corte também foram obras de D. Maria I.

A riqueza e a diversidade dos espólios régios vêm atraindo a atenção de investigadores nas mais diversas áreas do conhecimento. Arqueólogos, antropólogos e historiadores têm se debruçado sobre manuscritos e objetos materiais, na tentativa de compreender os usos e costumes das sociedades que nos precederam. Em Portugal, o reinado de D. João V tem sido largamente analisado, em função do seu perfil de colecionista e de mecenas, que imprimiu uma marca diferenciada na casa real setecentista. Interessa-nos, para este artigo, 
analisar o rol das encomendas que, de Lisboa, partiram com destino a Paris, as quais tiveram por interlocutores D. Vicente de Sousa Coutinho, embaixador português em Paris, e José António Pinto da Silva, moço da Câmara de Guarda-Roupas e Guarda-Joias da rainha.

Ao analisarmos a aquisição de bens materiais pela família real portuguesa, é preciso termos em consideração dois aspectos. Se, por um lado, muitos dos produtos encomendados aos embaixadores tinham como objetivo o uso direto e imediato (vestimentas, louças, tapeçarias), por outro, um elevado volume de bens era adquirido com o intuito de compor coleções. A exemplo disso, temos as numerosas encomendas feitas, no século XVIII, por D. João V, um exímio colecionador e mecenas das ciências e das artes, cujos bens adquiridos passaram a compor o espólio régio, tais como gravuras, quadros, estampas e mapas, que foram reunidos em grandes bibliotecas, nomeadamente as do convento de Mafra, do Colégio das Necessidades e da Universidade de Coimbra.

Fumaroli (2002) destaca que a intensa circulação de ideias - experienciada no século XVIII por alguns grupos sociais, nos quais se encontram os representantes diplomáticos -, foi responsável pelo surgimento de uma espécie de République des Savants et des Lettres. Segundo o autor, os Savants tiveram um papel fulcral na difusão do saber, da cultura e das letras. Conectados por meio desse ideal, poderiam ser nobres ou pertencentes a estratos sociais mais baixos. Júnia Furtado (2012), partindo da historiografia luso-brasileira, acabou por associar ao grupo de letrados ilustrados, do qual D. Luís da Cunha fazia parte, o conceito de estrangeirados - o qual, muitas vezes, foi utilizado de maneira depreciativa, ao acentuar a presença de ideias francesas em seus princípios e a inexistência de ligação entre eles e o reino. Há, contudo, investigadores que discordam do uso do termo "estrangeirado" para designar tais homens ilustrados. Para Serrão (1996), a atribuição desse conceito acaba por associar o período pós-Restauração portuguesa à falta de pensamento autônomo dos seus intelectuais.

Ao longo da leitura da documentação produzida em algumas embaixadas, é interessante considerar a dinâmica criada pelas encomendas, com a troca constante de correspondências entre funcionários da corte e embaixadores (Cardim, 2002). A correspondência assumiu um papel importante na aproximação dos interlocutores e no intercâmbio de ideias, bens e ações (Cluny, 
2006). Criou-se, a partir dela, uma sociabilidade que só seria possível existir num mundo de letrados, do qual os embaixadores faziam parte, uma vez que, simultaneamente à missão de representação, assumiam, também, a de informação (Furtado, 2012).

Louças da China, tecidos da Holanda, tapeçarias da Índia, entre outros objetos, poderiam ser encontrados nas listas de bens enviados das embaixadas, demonstrando a grande riqueza e diversidade e, ao mesmo tempo, a intensa circulação material da época. Além disso, nas cerimônias promovidas pelos embaixadores nas embaixadas, a ostentação da riqueza da corte que representavam podia ser vista no luxuoso aparato de bens que expunham aos seus convidados.

A correspondência (Chartier, 1998) entre os próprios embaixadores e, ainda, aquela trocada com funcionários régios, demonstram a importância que a aquisição de bens materiais provenientes do estrangeiro representou naquela sociedade. A composição das coleções - e, até mesmo, dos guarda-roupas, do mobiliário, dos objetos em ouro e prata que compunham a mesa dos reis - aponta para a intensa circulação de artigos, que permitiu aos seus detentores conhecer um pouco do mundo que os rodeava. Rendas, joias, sedas, adereços, mobiliários, tapeçarias ganhavam o mundo e proporcionavam a troca de hábitos culturais. Um mundo em constante movimento, que permitiu ao português, residente no Brasil, possuir camisas adornadas com rendas inglesas; e à dama portuguesa, residente em Portugal, possuir leques adornados com diamantes de Diamantina (Russell-Wood, 2006). Veremos, a seguir, a composição do guarda-roupa da Rainha D. Maria I e o papel desempenhado por um de seus embaixadores na aquisição de uma variedade de bens provenientes dos quatro cantos do mundo.

\section{O Embaixador e o guarda-roupas de D. MARIA I²: DA RENDA INGLESA AOS DIAMANTES DO BRASIL}

João António Pinto da Silva serviu à família real, ao longo de doze anos, na Cidade de Grão-Pará e no Maranhão. De volta a Portugal, foi oficial de Secretaria do Estado dos Negócios da Marinha e Domínios Ultramarinos e, nas duas últimas décadas do século XVIII, desempenhou, com "muita eficiência, honra e fidelidade", a função de Moço da Câmara de Guarda-Roupas, 
Guarda-joias e Tesoureiro dos Gastos Particulares e do Real bolsinho da Rainha. Pinto da Silva, quando da sua nomeação, disse que: “[...] por falecimento de Estevão Pinto de Moraes Sarmento foi o Senhor Rei Dom José, que está em Glória, servido nomear-me Guarda-Joias e Tesoureiro dos Gastos Particulares, e mais despesas do Paço; cuja honra me continuou também a Rainha Nossa Senhora" (Pinto da Silva, Livro 67, fl. 1, 1777).

Uma das incumbências de Pinto da Silva, na qualidade de guarda-roupas e guarda-joias, foi a de enviar as listas de encomendas de objetos solicitados pela rainha D. Maria I. Com o objetivo de analisar a composição do espólio régio, assim como os usos e costumes da sociedade de corte da época, será analisado, neste artigo, o livro de correspondências trocadas entre Pinto da Silva e o Embaixador Ordinário D. Vicente de Sousa Coutinho, pertencente ao acervo do Ministério dos Negócios Estrangeiros (MNE), sob a guarda dos Arquivos Nacionais da Torre do Tombo (ANTT), em Lisboa.

Na primeira década do século XXI, alguns estudos que utilizaram correspondências (cf. Cluny, 2006), sobretudo as diplomáticas, deram a conhecer os meandros de um meio social cujo corpus documental revelou-se bastante rico, mas que, até então, tinha sido pouco analisado. A partir daí, essa tipologia documental vem sendo objeto de estudo de historiadores, sociólogos e antropólogos, por ser considerada não somente como meio de transmissão de notícias, mas também uma maneira de permitir a sociabilidade entre os interlocutores.

Contudo, segundo Vázquez (2007), a utilização das correspondências como fontes documentais tem priorizado a produção de cartas de "agentes da primeira ordem no campo do poder", como os embaixadores, deixando de lado um conjunto de correspondências do período setecentista que não se enquadra nessa categoria. A inclusão das correspondências como fontes documentais, não somente para estudos literários, mas também para aqueles relacionados à história cultural e das ideias, é, para Vázquez, fundamental, uma vez que "[...] possibilitam o convívio e a troca de ideias, assim como o estabelecimento de vínculos estratégicos de cooperação entre os elementos dos diferentes campos da cultura e do poder." (Vázquez, 2007, p. 87).

Apesar de este artigo ter como objetivo analisar o conteúdo das encomendas, bem como a sua variedade e aplicação no contexto régio, é importante sublinhar-se que é possível, também, recuperarem-se aspectos da vida cotidia- 
na de ambas as cortes, assim como aspectos políticos inerentes à legação na corte parisiense. Foram frequentes, por exemplo, as referências feitas por Coutinho aos altos custos das encomendas e aos seus efeitos nas contas da legação. Era notório que a corte parisiense era a que reunia, naquela época, produtos luxuosos, matéria-prima de excelente qualidade e, também, especialistas na arte da ourivesaria, por exemplo (Silva, 2012). Tais constatações explicam a remessa de infindáveis listas de encomendas, enviadas não somente pelos monarcas portugueses. ${ }^{3}$

Comecemos, portanto, a analisar o teor da correspondência trocada entre Pinto da Silva e Coutinho entre os anos de 1777 e 1792 . O volume em questão é composto por 286 folhas manuscritas e assinadas por José Pinto da Silva. Apesar de Pinto da Silva ter assumido funções ainda no reinado de D. José, e após o terremoto de $1^{\circ}$ de novembro de 1755 , somente foi possível localizar as correspondências enviadas por ele 22 anos mais tarde, já no reinado de D. Maria I. Percebe-se, contudo, que os efeitos do terremoto nas condições de habitabilidade da família real ainda se faziam sentir, uma vez que ela residia na Real Barraca ${ }^{4}$, e algumas encomendas remetidas para Paris seriam utilizadas na adequação do Palácio da Ajuda, o qual seria utilizado como residência real. Pinto da Silva escreve a Coutinho sobre essa questão. Ele diz:

[...] estão suas Majestades vivendo em uma Barraca, tanto por ser menos perigosa para aqueles terríveis fenómenos como por não terem ainda Paço competente, e agora ate o mês de setembro, em que passarão para a Quinta de Queluz, me mandaram fazer umas obras na dita Barraca, para com mais comodezas do interior do Quarto da Rainha Nossa Senhora (Pinto da Silva, Livro 67, fl. 1, 1777).

Diante disso, a necessidade de reconstruir a residência real foi responsável por gerar um elevado número de cartas em que constavam encomendas de artigos de tapeçaria, louças, prataria, pinturas. Pinto da Silva justificava: “[...] como V. Excelência está em uma corte tão provida de tudo que pertence ao luxo, porque estas são as suas frutuosíssimas Minas" (Pinto da Silva, Livro 67, fl. 46,1784$)$.

Os gastos com a maioria das encomendas, feitas ao longo dos quinze anos de função de Pinto da Silva, foram pagos por Monsieur Juan Dupont, a pedido de Joaquim Pedro Quintela ${ }^{5}$, homem de negócio da praça lisboeta. Ao embaixador Vicente Coutinho cabia "[...] mandar comprar, ou fazer tudo com pron- 
tos pagamentos, vai neste mesmo correio ordem de Paulo Jorge, a Girardot Haller e Companhia ${ }^{6}$, para assistir a V. Excelência com todo o dinheiro" (Pinto da Silva, Livro 67, fl. 34, 1784). O recurso a entidades financeiras que garantissem o acesso aos meios necessários para a aquisição dos bens encomendados acabou por ser frequente ao longo dos anos em que Pinto da Silva e Coutinho se corresponderam.

A preocupação do guarda-roupas com a quantidade de dinheiro destinada às encomendas feitas na corte de Paris e com o bem-estar do embaixador era frequente, chegando Pinto da Silva a solicitar que Coutinho se manifestasse, explicitando que:

[...] se não achar próprio este modo de assistência, me queira avisar com sinceridade, e clareza do que devo fazer; porque eu só pretendo livrar a V. Excelência dos justos e penosos embaraços que costumam causar encomendas sem dinheiro; e para se poderem conservar sempre em ser as primeiras assistências (Pinto da Silva, Livro 67, fl. 39, 1784).

Interessa-nos, neste artigo, analisar os bens que compunham as listas de encomendas elaboradas por Pinto da Silva em nome de D. Maria I, e perceber a diversidade de artigos que fizeram parte do dia a dia da soberana portuguesa. Camisas de dia e noite, saias, meias de seda (bordadas com fio de ouro e prata), luvas, sapatos, chinelos e leques pintados na Rússia foram enviados da França para a corte em Lisboa. Ouro e diamantes também compunham as relações de Pinto da Silva, com indicações precisas para o seu uso.

[...] quando V. Excelência me remeter as duas caixas de Diamantes, que ai se mandaram fazer para irem para a Rússia, deverá mandar-me também outras duas caixas de ouro de bom gosto, que custam trinta moedas cada uma, ou o que $\mathrm{V}$. Excelência entender melhor, as quais deve levar dentro uns anéis que aqui se fizeram Pinto da Silva, Livro 67, fl. 39, 1784).

Sabe-se que, no século XVIII, o estatuto, o poder e a grandiosidade construíam-se, também, em função das aparências, ou seja, daquilo que era apresentado na vida pública da corte e nas cerimônias que a sociedade da corte vivenciava (Elias, 1987). Pinto da Silva chegou a fazer referência, por exemplo, à qualidade das carruagens utilizadas na corte, ressaltando que "[...] a multidão das gentes, que as vão ver às casas dos celeiros dá uma evidente prova de que 
elas se acham executadas no bom gosto" (Pinto da Silva, Livro 67, fl. 85-86, 1784). Percebe-se que, nessa centúria, o espetáculo e a teatralização fazem parte das cerimônias em vários momentos: a entrada dos embaixadores nas cortes estrangeiras, a apresentação das cartas credenciais aos reis, os casamentos, batismos e funerais, tudo era organizado e encenado ao pormenor.

Muito do prestígio, nesses espetáculos, estava relacionado com o luxo das indumentárias, com a diversidade da louça de servir, com os tapetes expostos nas salas de jantar, com as joias exibidas, com a exuberância dos adereços. A corte francesa era, como já foi dito anteriormente, a origem da maioria dos produtos que circulavam em Lisboa, chegando Pinto da Silva a afirmar: "[...] mas como V. Excelência está em uma corte tão provida de tudo que pertence ao luxo, porque estas são as suas frutuosíssimas Minas" (Pinto da Silva, Livro 67, fl. 46, 1784). Nuno Vassalo e Silva (2002), ao analisar um dos conjuntos de utensílios em prata de maior destaque do Portugal setecentista, pertencente à Casa de Aveiro, deixa claro que essa possibilidade de aquisição de bens luxuosos, seja pela família real, seja pelas principais casas senhoriais da época, teria sido bastante facilitada devido às condições econômicas observadas no século XVIII. O inventário da Mantearia do Duque de Aveiro é, segundo o autor, um exemplar importante para quem pretende analisar a aquisição de produtos de luxo nos setecentos.

No rol de encomendas - além de indumentárias de uso corrente e objetos diversos -, a aquisição de bens que eram presenteados a outros monarcas também fez parte das cartas enviadas por Pinto da Silva a Coutinho. Na verdade, a troca de presentes entre monarcas acabava por ser uma maneira de se fazer circular, pelas variadas partes do globo, uma grande diversidade de objetos. $\mathrm{O}$ casamento de D. Carlota Joaquina com D. João VI é um dos momentos em que é possível se qualificar e quantificar os bens remetidos pelo monarca português aos Reis Católicos. Entre os objetos enviados a Madrid estava um retrato do Infante D. João (no valor de 12:000\$000), que seria apresentado à Infanta Carlota no dia em que fossem feitas as escrituras. Além disso, é interessante observar, na listagem, o envio de presentes (sobretudo joias) a vários integrantes da comitiva que, provavelmente, assistiriam a Infanta: mordomos, camaristas, cirurgião, sangrador, médico, cavalariço, entre outros.

Um aspecto que salta aos olhos na correspondência entre Pinto da Silva e Coutinho é a referência que o guarda-joias faz, com alguma recorrência, à 
maneira cuidadosa - e, muitas vezes, meticulosa - com que o embaixador descrevia os objetos que eram enviados de Paris. Pinto da Silva chegou a afirmar que as descrições "[...] não devem ser com o excesso de miudezas, e escrúpulos com que V. Excelência mandou as dos Ornatos das Casas no ano de 1788, e deve poupar-se àquele trabalho, que nem é próprio da sua distintíssima pessoa nem do alto caracter que dignissimamente se ocupa." (Pinto da Silva, Livro 67, fl. 208, 1788). A mesma dedicação vista na correspondência de Coutinho também foi possível perceber naquela enviada por Tarouca ${ }^{7}$, no início do mesmo século. O empenho de ambos atesta, provavelmente, que, apesar de se dividirem entre as atividades de representação política e a de encomendeiros nos mercados especializados, havia a preocupação de desempenharem ambas as funções da melhor maneira possível.

A caracterização pormenorizada de muitos objetos encomendados pela rainha permite a visualização de uma parte dos bens que compuseram o seu espólio e, ainda, a diversidade de suas origens. Em 1777, Pinto da Silva escreveu ao embaixador solicitando que este providenciasse a D. Maria I dois toucadores (uma espécie de banco; mobiliário onde eram guardados os ornamentos femininos) feitos em prata dourada e "muito decentes" (Pinto da Silva, Livro 67, fl. 1v, 1777). Um deles seria usado no Paço, devendo, portanto, ser composto por todas as peças que costumam fazer parte do móvel. Já o segundo deveria ser portátil e "resumido de maneira", que pudesse ser utilizado em viagens pela via terrestre. Ambos, entretanto, teriam de estar à altura da "grandeza de Sua Majestade" (Pinto da Silva, Livro 67, fl. 1v, 1777), não sendo necessário que possuíssem o escudo real, o que tornaria possível o seu uso em qualquer ocasião. A orientação recebida por Coutinho com relação aos toucadores demonstra a importância dada à execução dos móveis e aos seus custos. Nas palavras de Pinto da Silva: "pelo que respeita aos preços; todos sabemos, que as coisas boas devem custar como tais; e que os artífices de reputação se costumam pagar à proporção dos seus merecimentos" (Pinto da Silva, Livro 67, fl. 2, 1777).

Não foram somente artigos para o uso pessoal de D. Maria I, contudo, que preencheram as correspondências enviadas por Pinto da Silva a Coutinho. Durante o período em que desempenhou a função de guarda-roupas como moço de câmara da rainha, a família real portuguesa vivenciou dois casamentos que ocorreram no mesmo ano, em 1785: o de D. João VI com a Infanta 
Dona Carlota Joaquina (filha de Carlos IV, da Espanha); e o de D. Mariana Vitória de Bragança ${ }^{8}$ com o Infante Gabriel, também descendente do trono espanhol.

Para a composição dos dois enxovais, foram enviadas listas específicas de artigos que o embaixador deveria adquirir na França. É interessante se observar a recomendação feita por Pinto da Silva a Coutinho para que este fosse cuidadoso e buscasse compor o enxoval de D. Carlota Joaquina de forma semelhante ao da Sereníssima Senhora Arquiduquesa D. Luiza Maria Teresa ${ }^{9}$ (soberana da Casa dos Habsburgos), cujo enxoval havia sido enviado ao embaixador português. Vestidos de seda, toucas de renda valenciana, mantos guarnecidos com rendas de prata e ouro, saias de brilhantes, meias, luvas, sapatos bordados em ouro e prata e leques fizeram parte da lista. Mais uma vez, diante do volume de encomendas que os preparativos para o casamento real acarretaram, constata-se a grande confiança que D. Maria I depositava no seu embaixador em Paris. Segundo Pinto da Silva, Sua Majestade tem

[...] toda a certeza de que tanto o enxoval, como as mais coisas, que confiou à disposição de V. Excelência, serão não só magnificas, e próprias, mas que V. Excelência se não pouparia a diligencia alguma para a sua magnificência, e gosto, e que por ter todas as provas da honra, zelo, e eficácia com que V. Excelência se emprega no seu Real Serviço (Pinto da Silva, Livro 67, fl. 46, 1784).

Ainda no ano que antecedeu o casamento de D. João VI, a família real portuguesa teve de preparar a hospedagem dos reis católicos, os quais acompanhariam até Portugal a sua neta, D. Carlota Joaquina. Cientes do aparato que seria necessário para hospedar "a tantos, e tão distintos hospedes", depois do terremoto de 1755 e dos seus efeitos no mobiliário e nos demais adereços presentes no palácio real, o moço da câmara da Rainha viu-se obrigado a recorrer, novamente, ao embaixador residente em Paris. A qualidade dos objetos produzidos em Portugal foi, mais uma vez, um dos motivos que levou Pinto da Silva a buscar Coutinho. As pratas, bastante utilizadas em todo o serviço de recepção aos hóspedes, apesar de estarem sendo confeccionadas em Portugal, aparentemente não estavam à altura de tão ilustres convidados.

Para o enxoval de D. Mariana Victoria de Bragança, a rainha mandou vir da França camisas de dia (de cambraia, guarnecidas de rendas finas); camisas de noite, de Olanda fina, guarnecidas de renda; saias de fustão; meias de seda; 
luvas de dedos, de couro branco; doze dúzias de pares de sapatos brancos e seda, bordados de ouro e prata; duas dúzias de leques (uma dúzia com panos pintados na Rússia e outra dúzia pintada na França), sendo as varetas deles feitas em Paris. Além disso, pedia que fossem enviadas amostras de sedas de todas as estações (das mais às menos custosas) e amostras de todas as fitas melhores, que estivessem na moda.

Na correspondência entre Pinto da Silva e Coutinho, as joias merecerão, entretanto, atenção especial, o que pode ser confirmado com a solicitação, por parte do guarda-roupas, de debuxos que deveriam ser enviados pelo embaixador. Tais esboços tinham como objetivo permitir que D. Maria I avaliasse a produção das peças, fazendo as interferências que julgasse necessárias. Percebe-se, assim, que as joias assumiram uma posição de destaque na composição dos bens da rainha e na sociedade setecentista. A descoberta do ouro e dos diamantes nas Minas Gerais garantiu a ornamentação das joias portuguesas com riqueza nunca vista. Sabe-se, entretanto, que os grandes centros de produção de peças em ourivesarias, no século XVIII, eram Roma, Augsburgo e Paris. Dentre eles, a cidade alemã foi, sem dúvida, aquela que assumiu maior importância no cenário europeu, em função de sua rede de ourives e de sua capacidade de distribuição das peças. Contudo, a partir do século XVIII, e com as volumosas encomendas feitas por D. João V, percebe-se que a corte francesa passou a receber a maioria dos pedidos oriundos de Lisboa. O monarca português, com grande frequência, recorria aos serviços de François Germain, ourives francês ${ }^{10}$ que foi responsável pela produção da primeira baixela real. (Jardim, 2012)

Em sua correspondência, Pinto da Silva deixou claros os motivos pelos quais a corte francesa era escolhida para produzir as peças em ouro para a família real. A mão-de-obra mais especializada que, segundo Pinto da Silva, existia naquela corte, era o fator principal a influenciar a escolha dos ourives franceses para a produção das joias da rainha. Em 1784, o guarda-joias chegou a afirmar a Coutinho que

[...] sendo nós os senhores dos Diamantes deveríamos fazer todas as joias guarnecidas destas pedras, mas a primeira dificuldade é no lavrado delas, porque em toda esta corte, não há mais que nove lapidários de brilhantes, e estes tão preguiçosos, que não lavram dez, ou doze pequenos. O segundo embaraço é dos ouri- 
ves, que as façam, porque não sendo também muitos, são raríssimos os bons (Pinto da Silva, Livro 67, fl. 87-88, 1784).

Figura 1: La Piéce de Corps - B

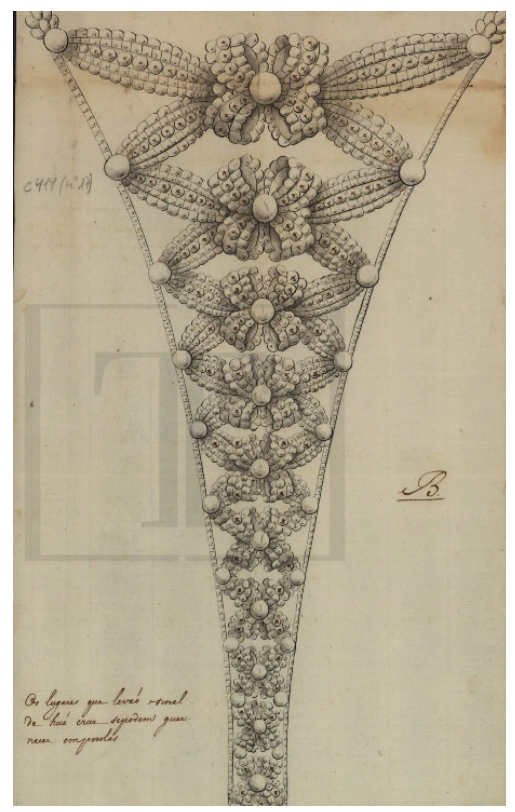

Fonte: La piéce de...

Percebe-se que, para a criação das joias, era preciso, antes, que fossem enviados debuxos da corte francesa, ou seja, desenhos feitos das peças que seriam criadas, os quais D. Maria I avaliaria, podendo ou não aprová-los. Para ajudar Coutinho, o moço de câmara de D. Maria I elaborou uma lista explicativa que permitisse ao embaixador visualizar o que era esperado constar nos debuxos das peças. O peitilho era, essencialmente, um ornamento de pedraria triangular, preso na roupa do peito à cintura, e a orientação de Pinto da Silva era a de que se pretendia “[...] saber o que poderá importar, e se haverá perolas para se concluir todo. E também se quer do mesmo modo saber a diferença que fará do custo sendo o dito Peitilho entrelaçado pelo meio com alguns brilhantes nos lugares de algumas perolas; e vindo todos assinalados com clareza, para aqui se poder perceber melhor" (Pinto da Silva, Livro 67, fl. 41, 1784). 
Figura 2: Colar

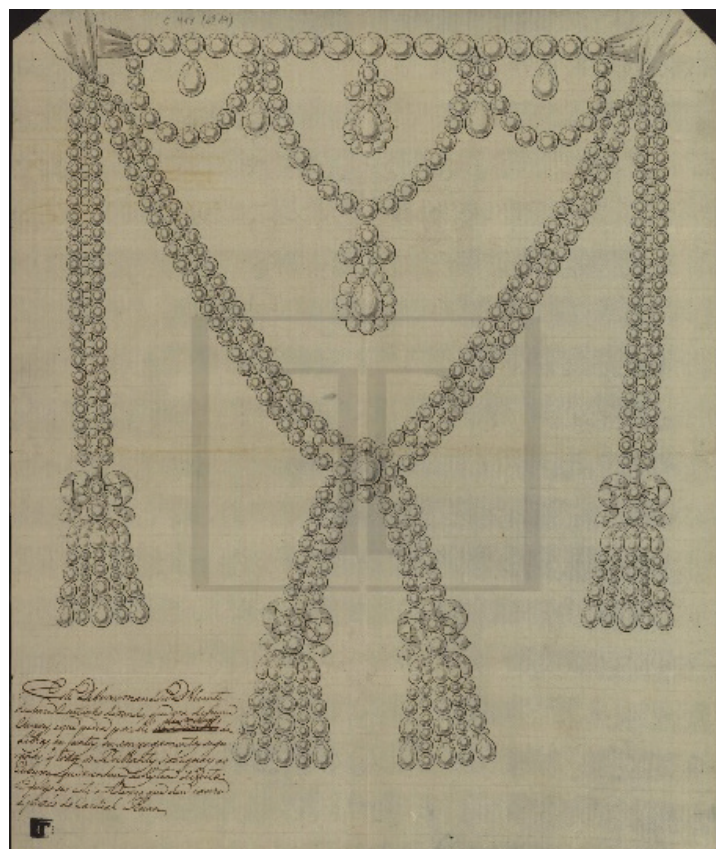

Fonte: Colar.

Já no que dizia respeito ao colar, o embaixador deveria informar o valor que ele poderia custar, assim como a sua composição de pedras e brilhantes. A orientação era que "[...] todos estes debuxos devem voltar com as explicações [...] e também os preços do importe de cada uma. Advertindo que tanto as perolas, como os diamantes se devem ai comprar; e não se remetem daqui, porque se devem cá fazer muitas outras joias" (Pinto da Silva, Livro 67, fl. 41, 1784).

\section{Conclusão}

A leitura das listas de encomendas enviadas por João António Pinto da Silva a D. Vicente de Sousa Coutinho, no período em que aquele atuou como guarda-roupas de D. Maria I, revelou um aspecto interessante e pouco analisado do papel assumido pelos agentes diplomáticos, que, em alguns casos, extrapolou o de representação do soberano nas cortes estrangeiras. D. Vicente de Sousa Coutinho, D. Luís da Cunha e o Conde de Tarouca foram alguns que, juntamen- 
te com a atividade diplomática, foram responsáveis por adquirir bens que passaram a compor as fortunas da família real e de membros da corte. ${ }^{11}$

A partir da leitura das cartas, percebe-se a confiança depositada pela rainha no bom gosto do embaixador e a certeza de que a corte parisiense era, naquele período, aquela em que se encontrariam os melhores e mais sofisticados produtos para compor o rol de bens régios. Os bens encomendados pela rainha, ao longo de quinze anos, permitem-nos, ainda, perceber a circularidade cultural e material daquele período: Rússia, Inglaterra, Índia, Holanda, Brasil e China foram alguns locais de onde partiram artigos adquiridos pelo embaixador e enviados a D. Maria I.

O século XVIII apresenta-se como um período de intensa circularidade de homens e de objetos, o que tornou possível a alguns portugueses residentes em Portugal possuir um lenço com bordado inglês ou um peitilho com diamantes do Brasil. Permitiu, ainda, que uma capela na Vila de Sabará possuísse adornos em seu altar com caracteres chineses. Apesar de a circulação material e humana não ter se iniciado naquela centúria, o século XVIII acabou por significar um incremento da tipologia e quantidade de bens que circulavam do Oceano Pacífico ao Atlântico, criando uma rede de comércio extremamente diversificada.

\section{REFERENNCIAS}

CARDIM, Pedro. Embaixadores e representantes diplomáticos da coroa portuguesa no século XVII. Cultura, vol. 15. Lisboa: Universidade Nova, pp. 47-86, 2002.

CHARTIER, Roger. A ordem dos livros: leitores, autores e bibliotecas na Europa entre os séculos XIV e XVIII. Brasília: UNB, 1998.

CLUNY, Isabel. O Conde de Tarouca e a Diplomacia na Época Moderna. Lisboa: Livros Horizontes, 2006.

COLAR (PT/TT/CR/3750/00017/000009). Disponível em: https://digitarq.arquivos. pt/details?id=7270808. Acesso em: 1 ago. 2020.

ELIAS, Norbert. A Sociedade de Corte. Lisboa: Editorial Estampa, 1987.

FUMAROLI, Marc. La Diplomatie de l'esprit. De Montaigne à La Fontaine. Paris: Gallimard, 2002.

FURTADO, Júnia. Oráculos da Geografia Iluminista: Dom Luís da Cunha e Jean-Baptiste Bourguignon D’Anville na construção da cartografia do Brasil. Belo Horizonte: Editora UFMG, 2012. 
FRANCO, Carlos José de Almeida. Casas das elites de Lisboa: objectos, interiores e vivências: 1750-1830. Tese (Doutoramento em Estudos do Património) - Universidade Católica Portuguesa, Lisboa, 2015. $524 \mathrm{f}$.

JARDIM, Maria do Rosário. A Baixela Germain ao serviço da Corte no Reinado de D. Maria I. Palácio Nacional da Ajuda - Artigos em Linha, n. 6, pp. 1-35, 2012.

LA PIÉCE DE Corps - B (PT/TT/CR/3750/00017/000002). Disponível em: https:// digitarq.arquivos.pt/viewer?id=7270801. Acesso em: 1 ago. 2020.

PINTO DA SILVA, João António. Correspondência do Guarda-Joias João António Pinto da Silva com D. Vicente de Sousa Coutinho. Livro 67, 286 fls. (Ministério dos Negócios Estrangeiros, MNE; Arquivos Nacionais da Torre do Tombo, ANTT). 1777- 1792.

RUSSELL-WOOD, Anthony John R. Um mundo em movimento. Lisboa: Difel, 2006. SERRÃO, Joaquim Veríssimo. Havia estrangeirados em Portugal?. In: BANHA, António Rodrigues. Vernei e a cultura de seu tempo. Coimbra, Editora da Universidade de Coimbra, v. 5, 1996. pp. 414-417.

SILVA, Nuno Vassallo e. Encomenda, uso e coleccionismo de ourivesaria no século XVIII: a mantearia da casa de Aveiro em 1752. Revista de História da Arte, Instituto de História da Arte - Faculdade de Ciências Sociais e Humanas/UNL, n. 9, pp. 69-91, 2012.

VÁZQUEZ, Raquel Bello. A correspondência na segunda metade do século XVIII como espaço de sociabilidade. Romance Notes, The University of North Carolina at Chapel Hill, Department of Romance Studies, vol. 48. n. 1, pp. 79-89, 2007.

\section{NOTAS}

${ }^{1}$ Este trabalho está inserido no âmbito do projeto "Entre a sobriedade portuguesa e o luxo das cortes europeias: os embaixadores portugueses e a circulação da cultura ilustrada", sendo financiado por fundos nacionais através da FCT - Fundação para a Ciência e a Tecnologia, I. P., no âmbito da celebração do contrato-programa previsto nos números 4, $5 \mathrm{e}$ 6 do art. 23 do D.L. n. 57/2016, de 29 de agosto, alterado pela Lei n. 57/2017, de 19 de julho. Investigadora Integrada no CHAM, Faculdade de Ciências Sociais e Humanas, FCSH, Universidade NOVA de Lisboa, 1069-061 Lisboa.

2 Maria Francisca Isabel Josefa Antónia Gertrudes Rita Joana de Bragança nasceu em 1734, sendo a primeira filha de D. José de Bragança. D. Maria I ficou conhecida na história por D. Maria, a louca, sendo seu primeiro ato, depois de assumir o trono, o exílio do Marquês de Pombal, pela forma como este tratou a família Távora. Com uma atividade legislativa comercial muito intensa, o seu reinado foi marcado pela criação de obras assistencialistas como a Casa Pia de Lisboa. Do seu casamento com Pedro III nasceram seis filhos: D. José I (1761-1788), D. João Francisco de Paula Domingos António Carlos Cipriano de Bragança (1763), D. João VI (1767-1826), D. Mariana Vitória (1768-1788), D. Maria Clementina 
Francisca Xavier de Paula Ana Josefa Antónia Domingas Feliciana Joana Michaela Julia de Bragança (1774-1776) e D. Maria Isabel de Bragança (1776-1777).

${ }^{3}$ Segundo Júnia Furtado, as compras efetuadas pela família real foram bastante volumosas ao longo de todo o século XVIII. No ano de 1759, por exemplo, cerca de 3.000 livros estavam em Paris, à espera de serem embarcados para Lisboa.

${ }^{4}$ A Real Barraca, ou Paço da Madeira, foi a residência oficial da família real após a destruição do Paço da Ribeira, com o terremoto de $1^{\circ}$ de novembro de 1755 . O Paço da Madeira recebeu esta denominação por ter sido construído em madeira, depois de D. João V recusar-se a habitar em uma residência de pedra. A família real residiu neste edifício até 1794, quando ele foi destruído por um incêndio. No mesmo lugar foi, depois, erguido o Paço Real de Nossa Senhora da Ajuda.

${ }^{5}$ Joaquim Pedro Quintela foi um dos grandes negociantes da praça lisboeta. Depois de herdar dos pais e dos tios maternos toda a fortuna, assumiu a posição de maior capitalista português da sua época. Com a reunião das duas fortunas, Quintela assumiu a titularidade dos contratos de tabaco, diamantes, azeite de peixe e baleia e das fábricas de lanifícios da Covilhã e Fundão. Tais contratos eram fontes de imensos lucros para Quintela, transformando-o num dos homens mais influentes da época, o que lhe rendeu a atribuição de honrarias: em 1793, foi nomeado fidalgo cavaleiro da Casa Real e, posteriormente, fidalgo do conselho da rainha D. Maria I, conselheiro honorário da Fazenda, comendador do Forno de Palhavã na Ordem de São Tiago da Espada e cavaleiro professo da Ordem de Cristo.

${ }^{6}$ Entidade bancária fundada no século XVIII por Isaac Vernet, Isaac de Thellusson e Daniel Girardot de Vermenoux, banqueiros em Genebra.

${ }^{7} \mathrm{O}$ Conde de Tarouca frequentava não somente os mercados especializados, mas também leilões, nos quais encontrava objetos que, pela sua raridade, eram vistos pelo embaixador como exemplares dignos de compor o espólio real.

${ }^{8}$ A Infanta D. Mariana Vitoria nasceu em 1768 e, do seu casamento com Gabriel António Francisco Xavier João Nepomuceno José Serafim Pascoal Salvador de Bourbon e Saxe, Infante de Espanha, nasceram três filhos, sendo dois rapazes e uma menina. Faleceu em 1788.

${ }^{9} \mathrm{Na}$ cópia da lista do enxoval da soberana da Casa dos Habsburgos constam, entre outras coisas, vestidos de diversas qualidades, mantos em seda guarnecidos com ouro, saias em cetim, punhos, guarnições para coletes, lençóis de cama, panos para apertar a cama, toalhas, peitilhos de várias cores e toucadores completos.

${ }^{10}$ No reinado de $\mathrm{D}$. João $\mathrm{V}$ foi encomendada à família Germain a baixela em prata que viria a se tornar um importante item da casa real portuguesa. A primeira baixela de Germain, contudo, acabou não sendo utilizada pelo monarca que a encomendou, em função do seu longo tempo de produção, tendo sido utilizada, pela primeira vez, apenas no reinado de D. Maria I.

${ }^{11}$ Apesar de este artigo não ter como objetivo analisar a composição das casas da elite portuguesa da época, torna-se importante referir que a composição do interior das casas sete- 
centistas, sobretudo lisboetas, assim como a vivência dessas casas, no que diz respeito à composição dos espólios, tende a acompanhar o que era visto na corte portuguesa. Uma análise dos inventários orfanológicos, por exemplo, poderia revelar a composição do espólio, assim como permitiria analisar até que ponto a corte portuguesa influenciou a aquisição de objetos por parte das elites do país, no intuito de viverem, no ambiente privado, aspectos da vida régia (Franco, 2015).

Artigo submetido em 02 de novembro de 2020. Aprovado em 06 de abril de 2021. 